\title{
Clinical risk factors for mortality of hospitalized patients with COVID-19: systematic review and meta-analysis
}

\author{
Guiling Xiang"^, Liang Xie", Zhihong Chen", Shengyu Hao, Cuiping Fu, Qinhan Wu, Xuhui Liu, \\ Shanqun Li
}

Department of Pulmonary and Critical Care Medicine, Zhongshan Hospital Fudan University, Shanghai, China

Contributions: (I) Conception and design: S Li, X Liu, G Xiang; (II) Administrative support: S Li, X Liu; (III) Provision of study materials or patients: S Hao, C Fu, Q Wu; (IV) Collection and assembly of data: G Xiang, L Xie, Z Chen; (V) Data analysis and interpretation: G Xiang; (VI) Manuscript writing: All authors; (VII) Final approval of manuscript: All authors.

\#These authors contributed equally to this work.

Correspondence to: Prof. Shanqun Li; Dr. Xuhui Liu. Department of Pulmonary and Critical Care Medicine, Zhongshan Hospital, Fudan University, 180 Fenglin Road, Shanghai 200032, China. Email: li.shanqun@zs-hospital.sh.cn; liuxuhui@shphc.org.cn.

Background New evidence from retrospective cohort studies on risk of death from COVID-19 infection became available. We aimed to systematically review the clinical risk factors for fatal outcome of COVID-19. Methods: We performed meta-analysis, using PubMed, EMBASE and Cochrane databases from December 12019 to June 10 2020. The meta-analysis summarized clinical, laboratory, radiological features, and complications of non-survivors with confirmed COVID-19. In addition, a fixed- or random-effects model was adopted based on the heterogeneity among studies. We also used funnel-plot with Egger's tests to screen potential publication bias.

Results: In total, twenty studies with 15,408 COVID-19 cases were included in our meta-analysis. Male, current smoking, and older age were associated with in-hospital death. Patients aged 60 years or over had the highest pooled ORs [OR $4.94(2.89,8.44)$ ]. Non-survivors were more likely to have diabetes, hypertension, cardiovascular disease (CVD), respiratory disease, or chronic kidney disease (CKD). Respiratory disease had the highest pooled ORs [OR $2.55(2.14,3.05)]$. Dyspnea [OR $3.31(1.78,6.16) ; \mathrm{I}^{2}: 83 \%$ ] and fatigue [OR 1.36 $\left.(1.07,1.73) ; \mathrm{I}^{2}: 0 \%\right]$ were associated with increased risk of death. Increased white blood cell count, decreased lymphocyte and platelet counts, were also associated with increased risk of death. Biomarkers of coagulation function, inflammation, liver and kidney function, cardiac and muscle injury were also elevated in nonsurvivors.

Conclusions: Male, current smoking patients aged 60 years or over might face a greater risk of in-hospital death and the comorbidities such as diabetes, hypertension, CVD, respiratory disease, and CKD could also influence the prognosis of the COVID-19. Clinical feature such as dyspnea and fatigue could imply the exacerbation and even death. Our findings highlighted early markers of mortality which were beneficial to identify fatal COVID-19.

Keywords: COVID-19; SARS-CoV-2; risk factor; mortality

Submitted Jun 18, 2020. Accepted for publication Dec 04, 2020.

doi: 10.21037/apm-20-1278

View this article at: http://dx.doi.org/10.21037/apm-20-1278

\footnotetext{
$\wedge$ ORCID: 0000-0001-5293-2908.
} 


\section{Introduction}

Coronaviruses are vital pathogens that are distributed widely among humans and other animals which could cause enteric, neurologic, respiratory illness ranging from the common cold to fatal infections (1). The two highly pathogenic human coronaviruses - severe acute respiratory syndrome coronavirus (SARS-CoV) and Middle East respiratory syndrome coronavirus (MERS-CoV) - are responsible for sometimes fatal diseases, SARS and MERS $(2,3)$. The pandemic of coronavirus infectious disease-2019 (COVID-19), caused by the severe acute respiratory coronavirus 2 (SARS-CoV-2), have been one of the most serious challenge to global health systems (4).

Compared to SARS (10\%) and MERS (30\%), the case fatality rate (CFR) of COVID-19 is much lower which is estimated at $0.66 \%(0.39 \%$ to $1.33 \%)(5,6)$. However, many more deaths are caused by COVID-19 ultimately as it has rapidly spread across the world than did the others, owing to rapid human-to-human transmission and atypical symptoms with highly contagious in certain patients $(7,8)$. In addition, the CFR is $30-70 \%$ for COVID-19 patients in intensive care unit (ICU) (9). Older patients with existing comorbidities have higher risk of death associated with COVID-19 (10).

Recently, numerous studies that have provided valuable data on demographic, clinical and laboratory features, complications, treatment and outcomes of inpatients with COVID-19, but the information is somewhat incomplete, part of them are low quality, and there are potential bias and residual confounding. Previous systematic review has merely integrated clinical and laboratory feature for nonsurvivors with COVID-19 from 4 Chinese studies (11). Many other important meta-analyses showed the risk factors of severity and mortality in COVID-19, including lab and imaging results (12-15), comorbidities (16-21) and medication use $(22,23)$. But these reviews with limited sample size tended to combine the severity/critical patients with non-survivors leading to risk of bias. Tian et al. (24) reported COVID-19 patients with cardiometabolic disease and evidence for acute inflammation and end-organ damage are at higher risk of mortality. Although they included 14 studies, but patients enrolled in several studies were from the same hospital with time-overlapping which have potential bias and lead to unreliable results. By the same token, Parohan et al. (25) included studies which integrated information of deaths and critical/ICU patients. In addition, many of these studies were from pre-print datasets without peer-review. Due to limited articles available, their metaanalysis elucidated demographic feature and comorbidities of mortality. With an increased amount of studies published, we performed a more comprehensive meta-analysis about clinical, laboratory, radiological features, treatment and outcomes of non-survivors with COVID-19 which may help clinical physician make more sound decisions.

We present the following article in accordance with the PRISMA reporting checklist (available at http://dx.doi. org/10.21037/apm-20-1278).

\section{Methods}

The protocols of meta-analysis have been registrated in PROSPERO (CRD42020183514) (26).

\section{Study selection and inclusion criteria}

Our meta-analysis focus on the risk factors of mortality in patients with COVID-19. We searched PubMed, EMBASE and Cochrane carefully using keyword: "COVID*", OR "NCP*", OR "SARS-CoV-2", "coronavirus", OR "pneumonia", OR " $\mathrm{nCoV}$ ", OR "HCoV", from December 12019 to June 10 2020. The search strategy was supplemented by retrieving medRxiv (https://www. medrxiv.org) and the references of included studies. Two investigators (GX and LX) independently evaluated search results and identified selected studies. Controversy was resolved by a third investigator (ZC). We follow Preferred Reporting Items for Systematic Reviews and Meta-Analyses (PRISMA) statement for conducting this meta-analysis (26).

We included studies met the following criteria: (I) hospitalized patients with confirmed COVID-19; (II) reported demographical, clinical feature, laboratory values, chest CT findings, treatment or outcomes of survivors and non-survivors respectively; (III) the risk factor of mortality; (IV) cross-sectional studies and (V) article language was English and/or Chinese. Studies which may enroll the same patients were evaluated by two reviewers and only one with priority was included. We also excluded studies without available data.

\section{Data collection and quality assessment}

Two investigators (GX and LX) extracted the following information for each identified study: (I) 1st author; (II) hospital; (III) sample size; (IV) demographic characteristics; (V) co-morbidities; (VI) clinical features; (VII) severity type; 
(VIII) laboratory and chest CT findings; (IX) complications; and $(\mathrm{X})$ treatment and outcome (e.g., hospital length of stay). Primary outcome measure was to compare the demographic features, prevalence of co-morbidities and comorbidities between deceased and alive cases. Secondary outcomes were compared the incidence of symptoms and laboratory findings between deceased and alive subjects. NewcastleOttawa scale (NOS) was followed to assess the methodological quality (27). This scale has 11 evaluation criteria, including cohort representability, selection of non-exposed cohort, ascertainment of exposure, outcome not present at baseline, comparability of cohorts for important factors, comparability of cohorts for other variables, assessment of outcome, followup long enough for outcome to occur, adequacy of follow-up. We gauged each study on a scale of zero to 9 and considered studies with NOS score $\geq 6$ as high quality. The checklist of the Agency for Healthcare Research and Quality (AHRQ) was also used to assess the quality and bias risk of the included studies. This scale includes source of information, inclusion and exclusion criteria, time periods, consecutive subjects, mask of subjective components, quality assurance, explanation of exclusions, control of confounding factors, method of handling missing data, completeness of data collection, and follow-up. An item is scored as 1 if included in the article and 0 if not. A score of 8 or more is indicative of a high-quality study. Because no RCT investigating the risk factor of mortality was retrieved in our search, no quality assessment tool for RCTs was used in the current meta-analysis. Discrepancies were resolved by discussion in group conference.

\section{Statistical analysis}

We used odds ratios (OR) with $95 \%$ confidential intervals (CI) for categorical variables. In addition, continuous variables were compared by calculating mean differences (MD) or standardized mean difference (SMD), when applicable. The pooled results presented as forest plot using the fixed- or random-effect models. Publication bias was identified using funnel-plot and Egger's tests. Sensitivity or subgroup analyses were performed to handle heterogeneity. The meta-analyses were performed using Stata software version 15.1 (Stata Corp, College Station, TX, USA).

\section{Results}

\section{Search result and study characteristics}

We identified 3,833 studies and then excluded 571 duplicate articles. The remainder were sifted by 2 investigators (GX and LX) who identified 731 articles relevant reports after reviewing titles and abstracts. Finally, 20 studies, including 1,970 non-survivors and 13,438 survivors, met our selection criteria and included (28-47). We excluded studies from the same hospital to avoid data duplication (Figure S1). The sample sizes among selected studies ranged from 19 to 8,910 . Studies were conducted in Hubei [Wuhan (28-31,33-35,41-44) and Huanggang $(32,33)]$, three continents (Asia, Europe, and North America) (36), New York (37,38), England (46), Italian (40,45) and Poland (39). Overall study quality, scored 6 to 9 according to the NOS and scored 8 to 10 according to the AHRQ, were considered high (Table 1 and Table S1). Our study has language bias, because Chinese databases were not searched.

\section{Demographical characteristics and comorbidities}

In Table 1 and Figure 1, we summarize the demographical characteristics and prevalence of comorbidities. The pooled results showed that sex [OR $0.66(0.59,0.73) ; \mathrm{I}^{2}$ : $29.3 \%$ ], current smoking [OR $1.51(1.23,1.85) ; I^{2}: 32.7 \%$ ], and patients aged 60 years or over [OR $4.94(2.89,8.44)$; $\left.I^{2}: 86 \%\right]$ were associated with fatal outcome. In Figure 2, we found an increased risk for mortality in patients with diabetes [OR 1.63 (1.44, 1.85); I': 29.1\%], hypertension [OR $\left.2.26(1.73,2.95) ; \mathrm{I}^{2}: 77.4 \%\right]$, cardiovascular disease (CVD) [OR $2.52(2.21,2.89) ; \mathrm{I}^{2}: 49.6 \%$ ], respiratory disease [OR 2.55 (2.14, 3.05); I': 37.2\%], chronic kidney disease (CKD) [OR $\left.1.82(1.46,2.28) ; \mathrm{I}^{2}: 0 \%\right]$, and cancer [OR 1.43 (1.12, $\left.1.82) ; \mathrm{I}^{2}: 37.1 \%\right]$.

None potential publication bias was found regarding mortality of COVID-19 in sex $(\mathrm{P}=0.202)$, diabetes $(\mathrm{P}=0.075)$, respiratory disease $(\mathrm{P}=0.610)$ and cancer $(\mathrm{P}=0.128)$, on the contrary in CVD $(\mathrm{P}=0.020)$, diabetes $(\mathrm{P}=0.038)$ and hypertension $(\mathrm{P}=0.007)$ with several studies beyond the $95 \% \mathrm{CI}$ (Figure S2).

OR or HR values regarding the risk of in-hospital death were extracted from 8 studies. The OR values extracted from included articles were all unadjusted. We found that older age, male, and CVD were associated with increased odds of death (Figure 3).

\section{Clinical manifestations and laboratory findings}

In Table 2, we summarize the clinical manifestations. This meta-analysis showed that dyspnea [OR $3.31(1.78,6.16)$; $\left.\mathrm{I}^{2}: 83 \%\right]$ and fatigue [OR $\left.1.36(1.07,1.73) ; \mathrm{I}^{2}: 0 \%\right]$ were associated with an increased risk for COVID-19 related mortality (Table 3). 


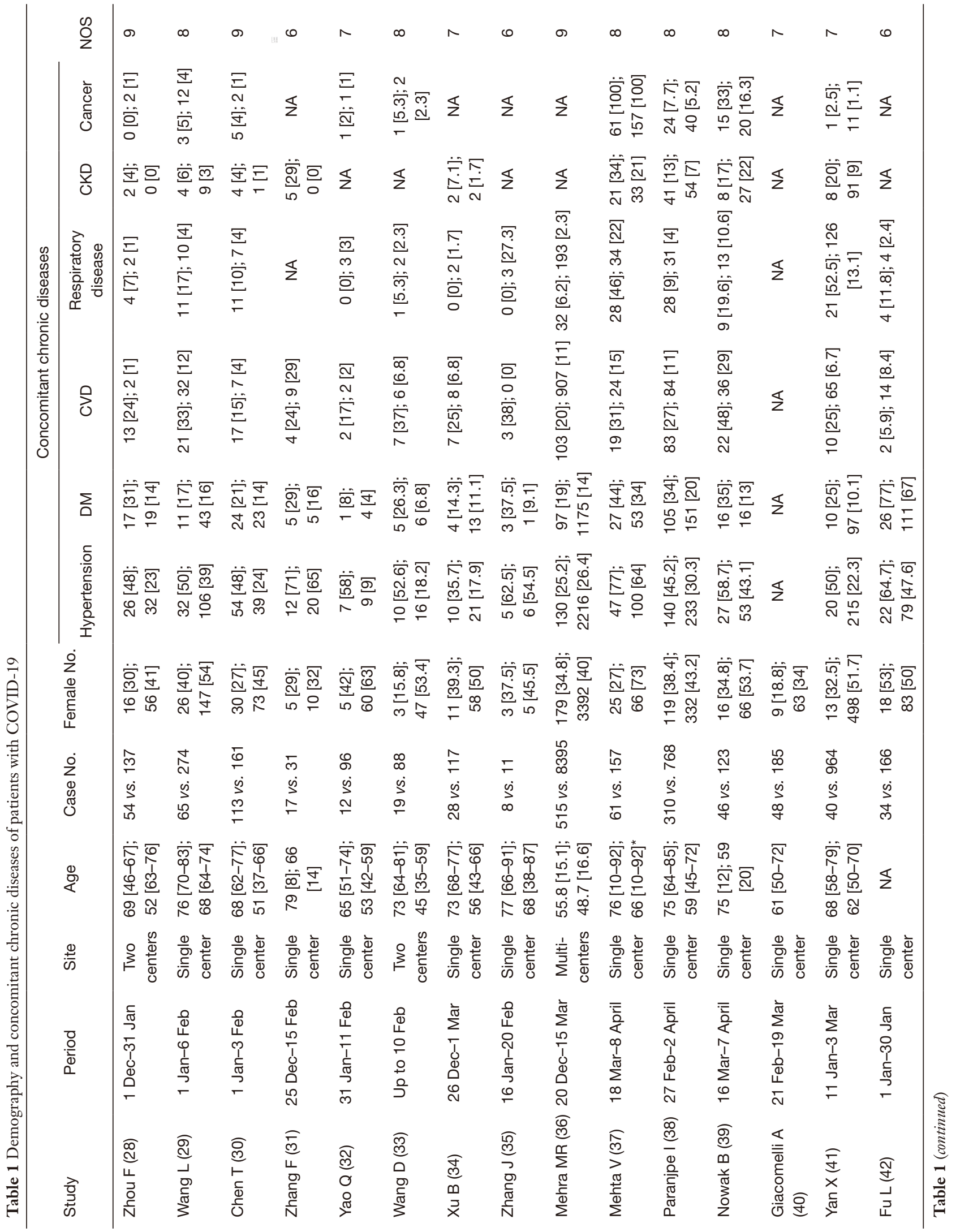




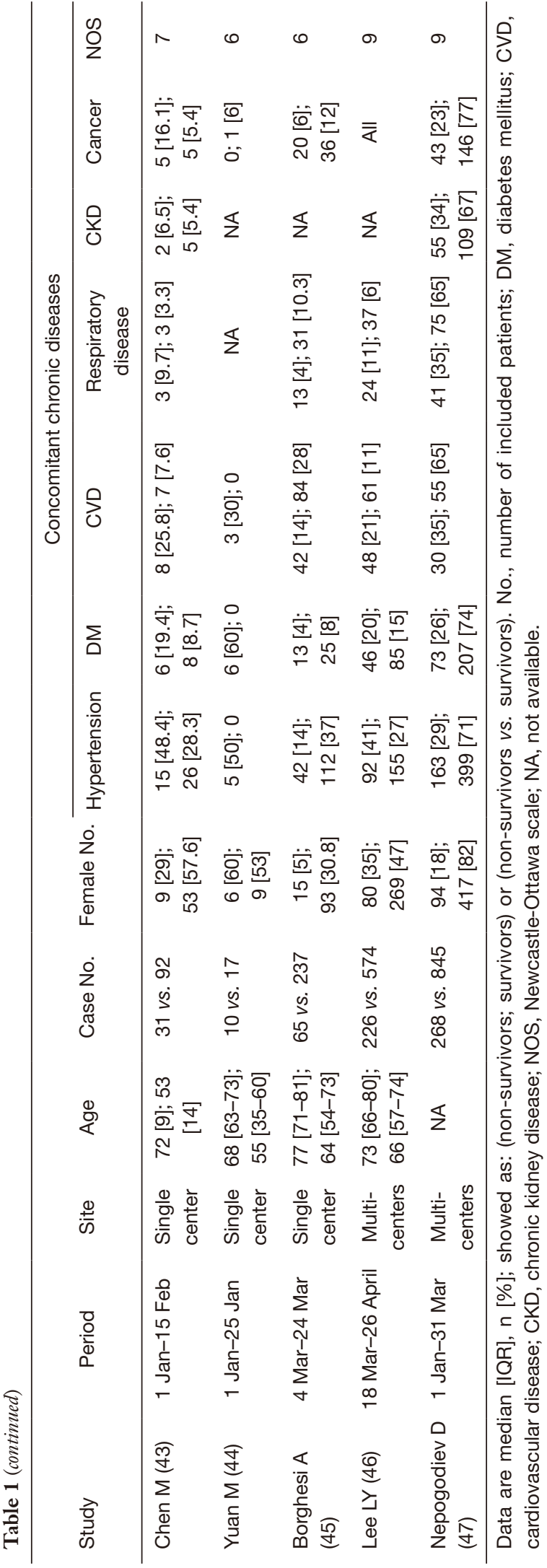

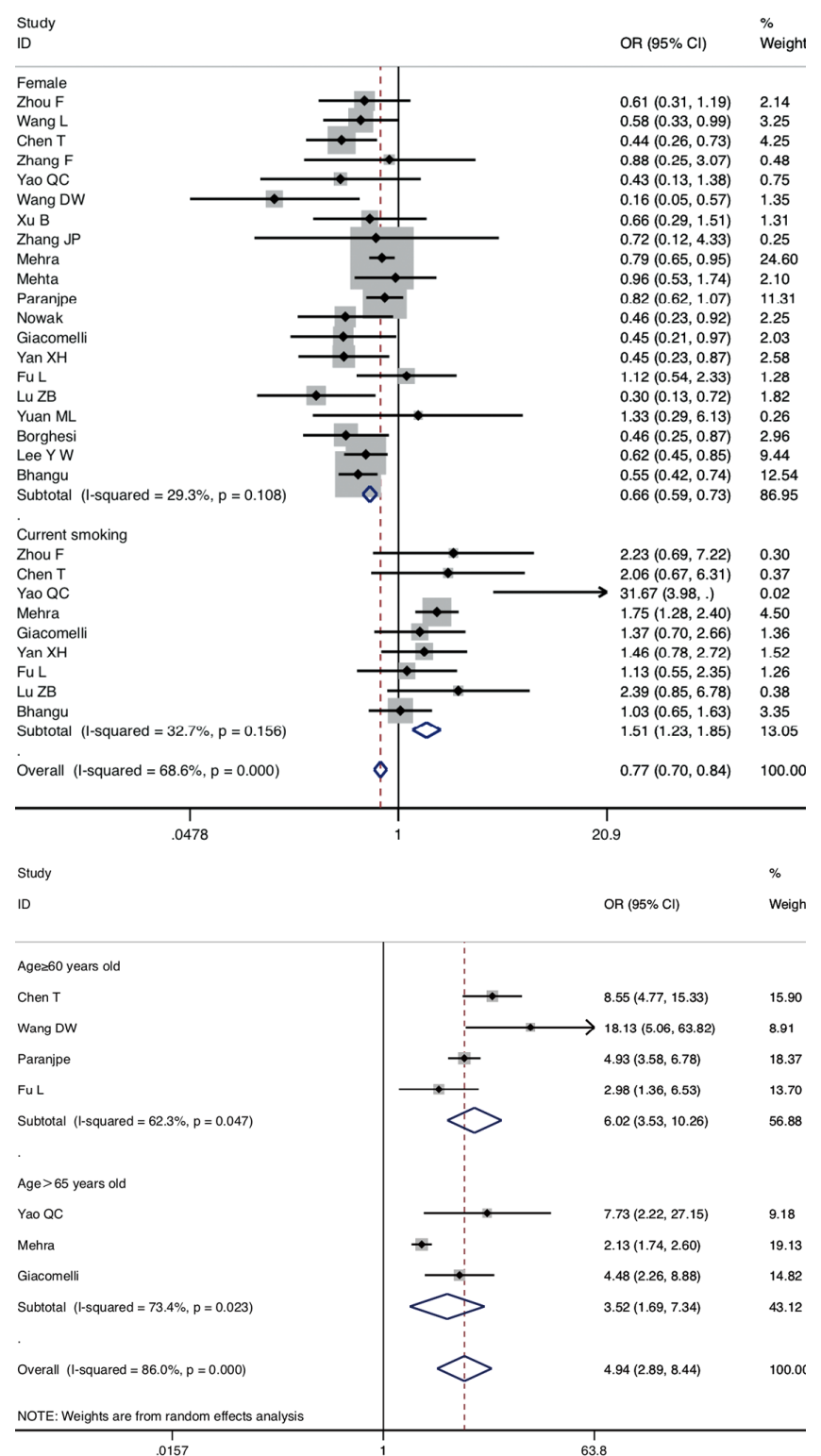

Figure 1 Forest plots of female, current smoking and age in nonsurvivors $v s$. survivors.

As shown in Figures 4 and S3, non-survivors had increased levels of white blood cells (WBC) [WMD 3.66 $\left.(2.58,4.74) ; \mathrm{I}^{2}: 88.7 \%\right]$, neutrophils [WMD $4.07(2.34$, 5.80); $\mathrm{I}^{2}: 90.7 \%$ ], prothrombin (PT) [SMD $0.6(0.31$, $0.89) ; \mathrm{I}^{2}: 87.1 \%$ ], D-dimer [SMD $0.77(0.46,1.07) ; \mathrm{I}^{2}$ : 91\%], C-reactive protein (CRP) [SMD $1.33(1.01,1.64)$; $\left.\mathrm{I}^{2}: 85.7 \%\right]$, procalcitonin (PCT) [SMD $1(0.68,1.31) ; \mathrm{I}^{2}$ : $84.4 \%]$, interleukin 6 (IL-6) [SMD 1.25 (0.84, 1.65); $\mathrm{I}^{2}$ : $84.2 \%]$, as well as albumin, alanine aminotransferase (ALT), 


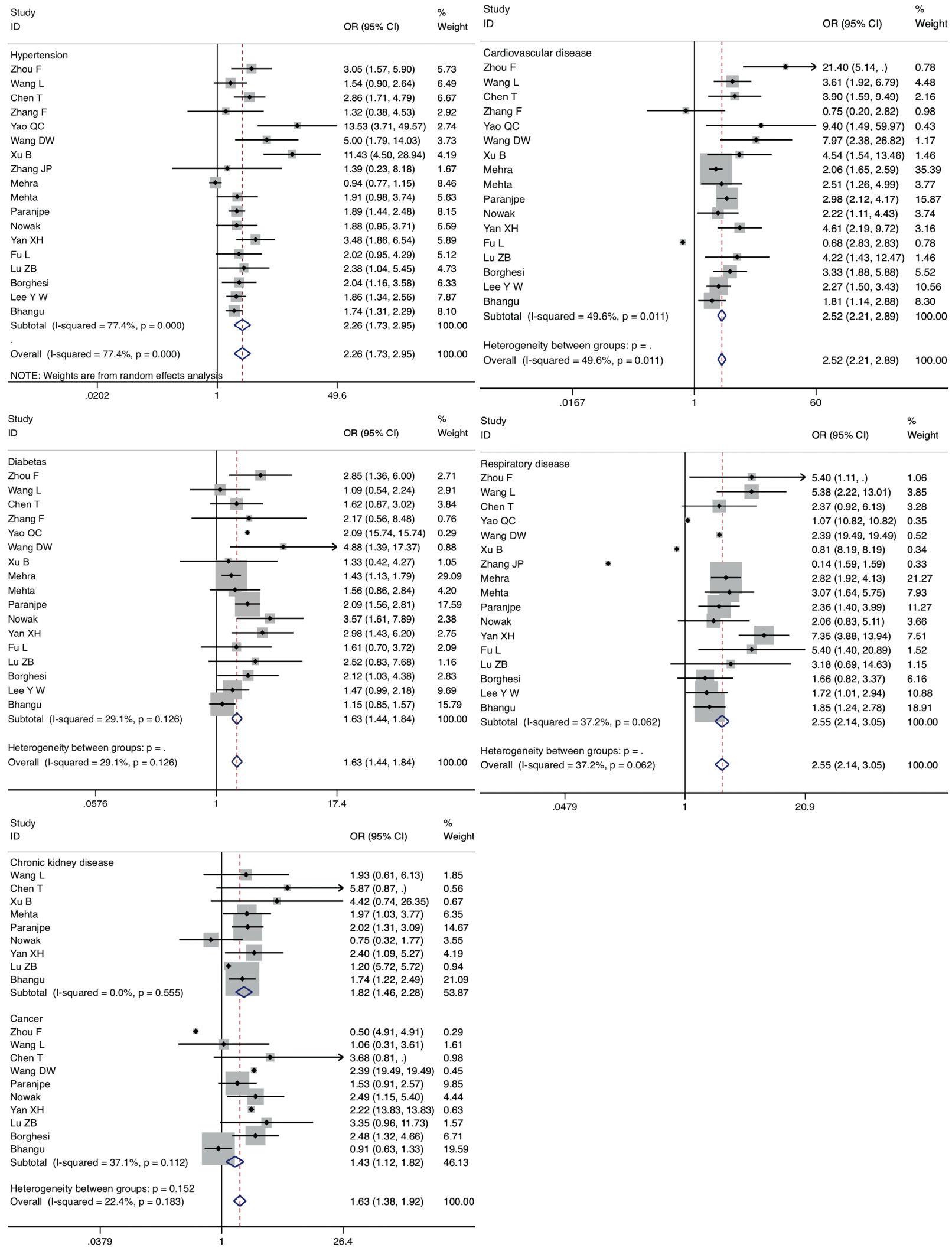

Figure 2 Forest plots of underlying diseases in non-survivors $v s$. survivors. 


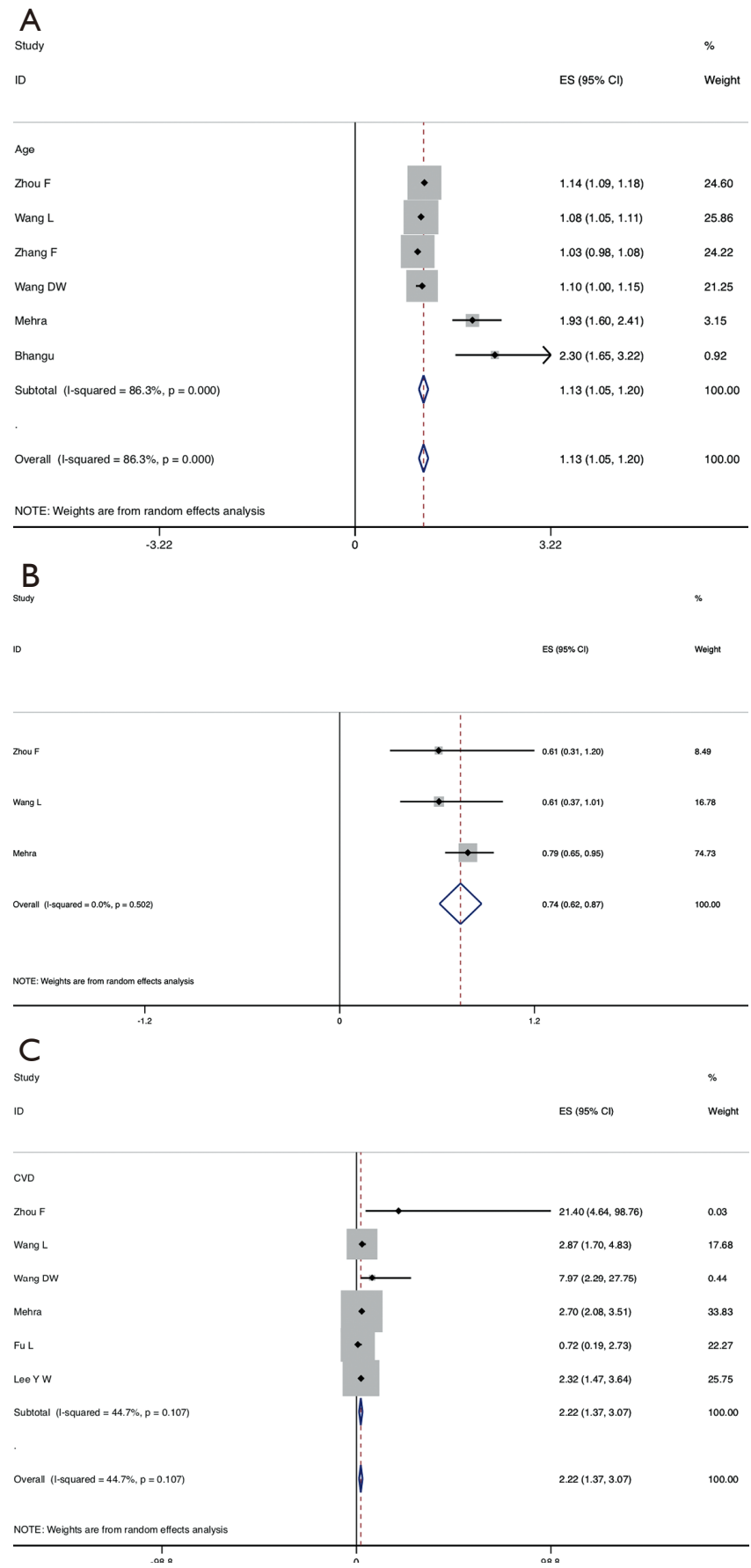

Figure 3 Forest plots of pooled OR regarding age (A), female (B), and cardiovascular disease $(\mathrm{C})$.

creatinine, lactate dehydrogenase (LDH), and creatine kinase (CK). Decreased counts of lymphocytes [WMD $\left.-0.3(-0.43,-0.17) ; \mathrm{I}^{2}: 92.8 \%\right]$, and platelet [WMD -34.8 $\left.(-50.88,-18.72) ; I^{2}: 84 \%\right]$ were also associated with in- hospital death.

\section{Complications}

The Table S2 shows the detailed summary comparing complications between non-survivors and survivors with COVID-19. The complications secondary to SARS-CoV-2 infection were more common in non-survivors including ARDS, sepsis, respiratory failure, heart failure, septic shock, acute cardiac injury, acute kidney injury and secondary infection compared to survivors.

\section{Discussion}

This study aimed to identify the risk factor of mortality associated with COVID-19. As we know, our meta-analysis included more patients with higher quality compared to previous meta-analysis $(24,25)$. The results of this metaanalysis demonstrated that current smoking, male, aged 60 years or over might face a greater risk of in-hospital death and the comorbidities such as diabetes, hypertension, CVD, respiratory disease, and CKD could also influence the prognosis of the COVID-19. Clinical feature such as dyspnea or fatigue could imply the exacerbation. Our findings highlighted early markers of mortality which were beneficial to identify fatal COVID-19.

The course of SARS-CoV-2 infection can be broadly separated into three stages: first-stage, asymptomatic incubation period and virus may not be detected; secondstage, mild symptomatic period with detectable virus; finalstage, severe symptomatic stage, viral load is higher and the duration is longer $(10,48)$. Around $15 \%$ of COVID-19 cases deteriorate to severe symptomatic phase, besides patients over 65 are more likely to develop severe illness (49). The question remained unresolved is why certain people progress severe disease and even die. Angiotensin-converting enzyme 2 (ACE2) receptor is a key target for SARS-CoV, and molecular modelling has indicated the structure of receptorbinding domains (RBD) of SARS-CoV and 2019-nCoV are strikingly similar (4). Though anchoring to the RBD, SARS$\mathrm{CoV}-2$ invade host cells especially in gastrointestinal, kidney, myocardial, and lung tissue leading to an exuberant immune response and enhanced cytokine release, named cytokine release syndrome (CRS), both contributed to multi-organ damage in severe COVID-19 patients (49).

Previous study reported that comorbidities could increase the mortality risk of SARS-CoV, and cardiac disease was strong predictor for adverse outcomes (50). Our findings 
Table 2 Clinical characteristics of patients with COVID-19

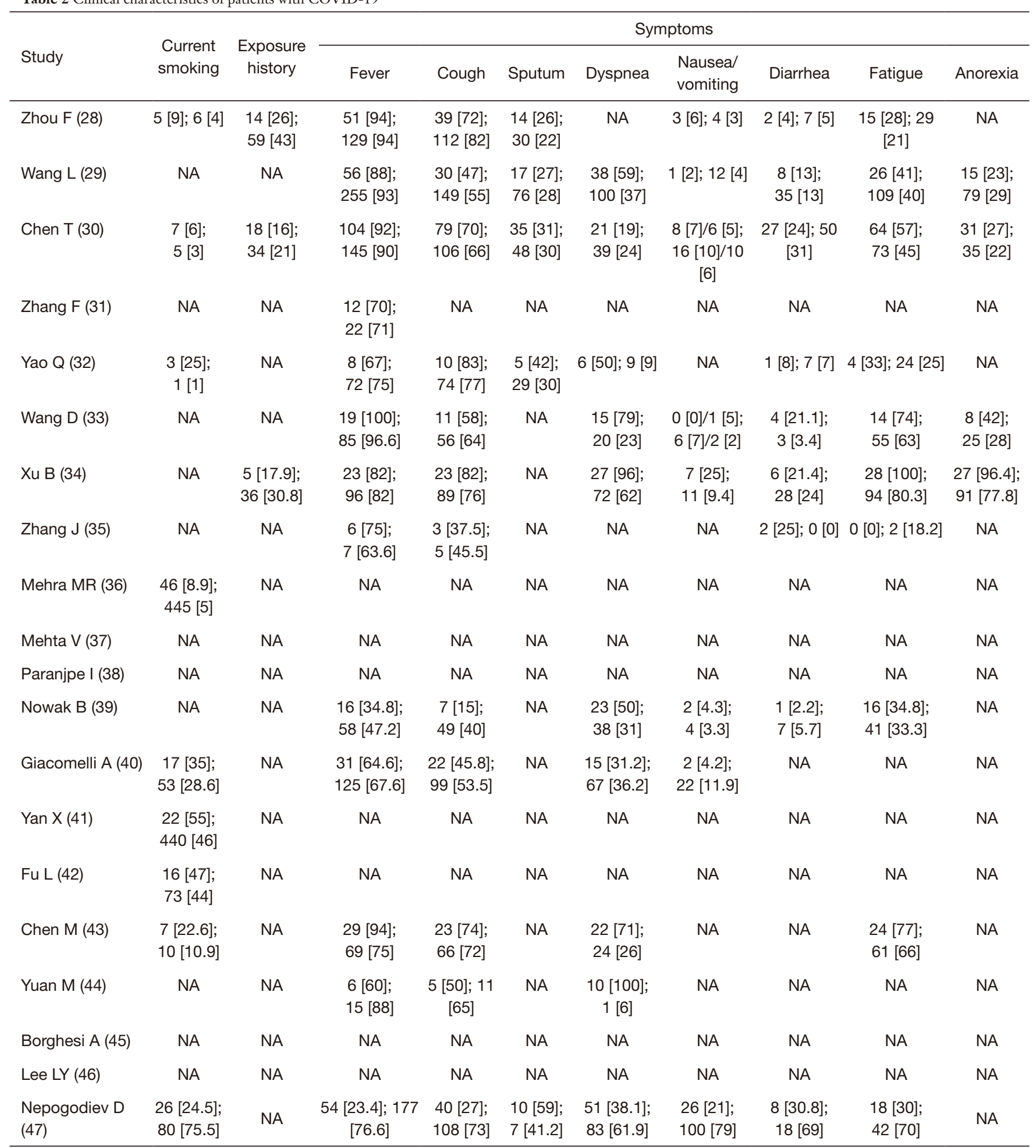

Data are median [IQR], n [\%]; showed as: non-survivors; survivors or non-survivors vs. survivors. In the two studies, patients were reported as nausea and vomiting, separately. NA, not available. 
Table 3 Results of meta-analysis comparing symptoms in non-survivors and survivors with COVID-19

\begin{tabular}{|c|c|c|c|c|c|c|c|}
\hline Symptoms & Studies & Patients & \multicolumn{2}{|c|}{ Heterogeneity } & Model & OR $(95 \% \mathrm{Cl})$ & $\mathrm{P}$ \\
\hline Fever & 13 & 2,895 & 13.4 & 0.310 & Fixed & $0.85(0.67-1.06)$ & 0.151 \\
\hline Cough & 12 & 2,848 & 25.1 & 0.197 & Fixed & $0.89(0.73-1.10)$ & 0.286 \\
\hline Sputum & 5 & 912 & 52.8 & 0.076 & Random & $1.40(0.86-2.29)$ & 0.179 \\
\hline Diarrhea & 9 & 2,465 & 29.8 & 0.180 & Fixed & $0.97(0.69-1.37)$ & 0.871 \\
\hline Fatigue & 10 & 2,588 & 0 & 0.798 & Fixed & $1.36(1.07-1.73)$ & 0.012 \\
\hline
\end{tabular}

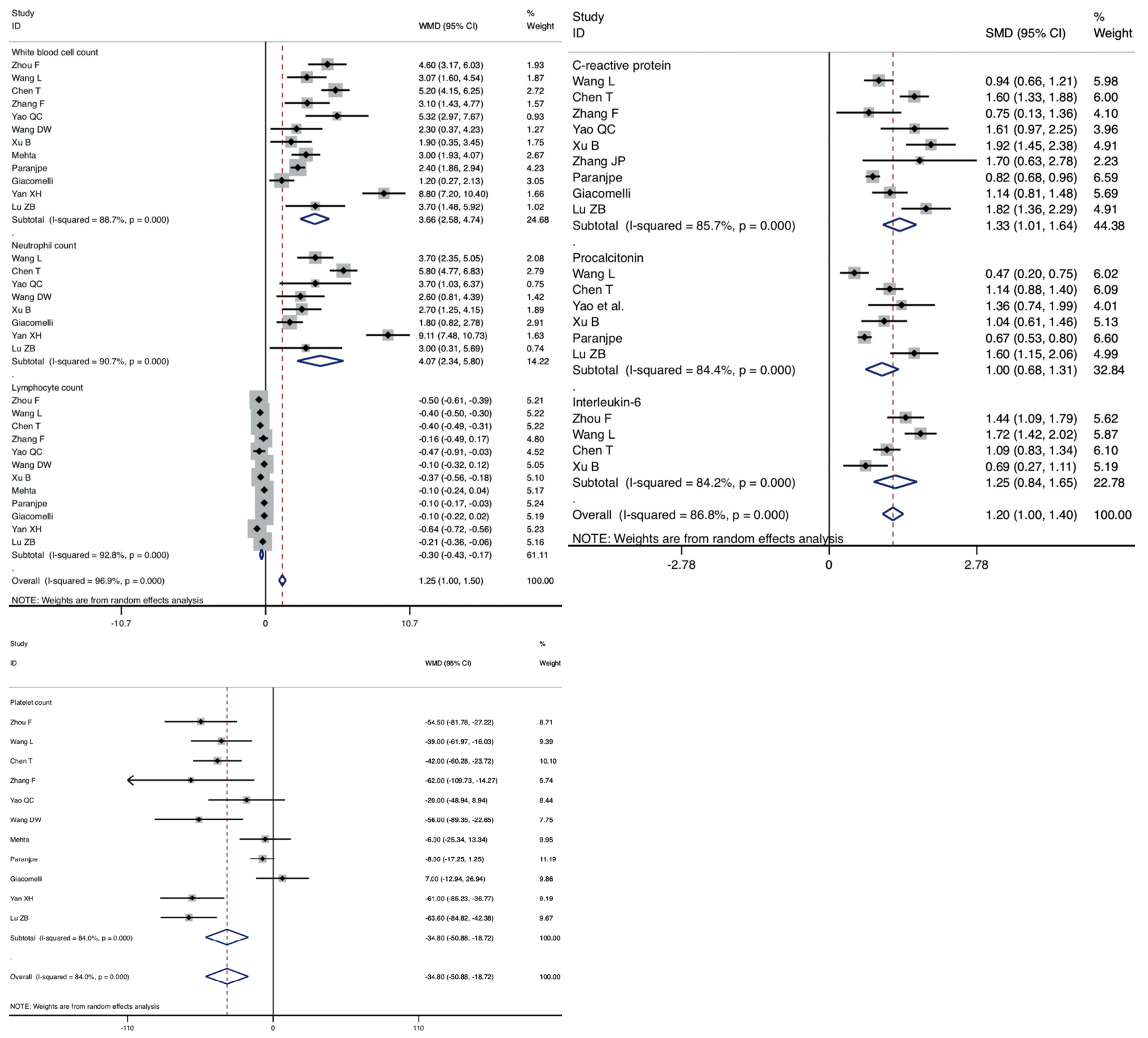

Figure 4 Forest plots of laboratory findings in non-survivors $v s$. survivors. 
also indicated prevalence of comorbidities was higher in the deceased compared to the survivors, CVD could increase over 3-fold risk of death. Indeed, biomarkers of inflammation, liver and kidney function, cardiac and muscle injury were also elevated in non-survivors of COVID-19. We supposed that chronic inflammatory conditions caused by comorbidities such as CVD, diabetes, and hypertension has been aggravated leading to death by SARS-CoV-2 infection. Moreover, older age as risk factor of death probably because of weak immune system. Our findings are consistent with previous studies $(51,52)$.

Pulmonary inflammatory response induced by S-protein of SARS-CoV-2 leading to alveolar damage, lung edema, compromised gas exchange, and progressive dyspnea. Prevalence of complications like sepsis, ARDS and shock were higher in non-survivors compared to survivors with COVID-19. Although the predominant complaint for COVID-19 patients was fever rather than dyspnea which is associated with 4-fold increase in the risk of death (53). The early recognition of dyspnea can help identify patients with poor prognosis. Interestingly, our meta-analysis showed that current smoking could increase about 2-fold risk of death. The reason, we speculate, may be that smoke could damage lung function, make it harder for infected patients to build up resistance to the virus and other diseases (54). In addition, males are more likely to smoke and suffer from chronic diseases which may contribute to mortality. We found thrombocytopenia, prolonged PT, and increased D-dimer in the deceased which is danger signal of DIC. In a multicenter study of 150 consecutive patients with COVID-19, Helms et al. (55) reported that plenty of COVID-19 patients developed ARDS had potentially fatal thrombotic complications. Anticoagulation should probably be suggested for critically ill patients with COVID-19. Rigorous randomized controlled trials are urgently needed to confirm these results.

Our review has limitations. This review can only provide results up to June 2020. However, we believe that new publications do not modify the trend and the main characteristics found for the disease. There was considerable heterogeneity in the data, which we interpret not to be due to major publication bias, or because of the heterogeneity of the disease itself. Moreover, evidence from early outbreaks and developing countries is limited duo to inadequate clinical treatment services resources. The present study is limited because of a focus on clinical factors only. These should guide us to pertinent questions for further study.

\section{Conclusions}

Our meta-analysis indicated that 60 years and older, male, current smoking, chronic complications, dyspnea or fatigue at illness onset, increased white blood cell count, neutrophils and IL-6 levels, lymphopenia, inflammation including increased CRP and PCT levels, liver and kidney dysfunction, cardiac and muscle injury, coagulation dysfunction including thrombocytopenia, prolonged PT, increased D-dimer level are important predictors for death in COVID-19 patients. In addition, patients who develop ARDS, sepsis, respiratory failure, heart failure, septic shock, and secondary infection have higher mortality risk.

\section{Acknowledgments}

The wordings of the main text and/or figures/tables have been checked by a native English-speaking expert and we appreciate the assistant of the following web https://app. grammarly.com/.

Funding: This work was supported by grants from The National Key Research and Development Program of China (No. 2018YFC1313600) and the National Natural Science Foundation of China (No. 82070094, 81570081, 81770083).

\section{Footnote}

Reporting Checklist: The authors have completed the PRISMA reporting checklist. Available at http://dx.doi. org/10.21037/apm-20-1278

Conflicts of Interest: All authors have completed the ICMJE uniform disclosure form (available at http://dx.doi. org/10.21037/apm-20-1278). The authors have no conflicts of interest to declare.

Ethical Statement: The authors are accountable for all aspects of the work in ensuring that questions related to the accuracy or integrity of any part of the work are appropriately investigated and resolved.

Open Access Statement: This is an Open Access article distributed in accordance with the Creative Commons Attribution-NonCommercial-NoDerivs 4.0 International License (CC BY-NC-ND 4.0), which permits the noncommercial replication and distribution of the article with the strict proviso that no changes or edits are made and 
the original work is properly cited (including links to both the formal publication through the relevant DOI and the license). See: https://creativecommons.org/licenses/by-ncnd/4.0/.

\section{References}

1. Su S, Wong G, Shi W, et al. Epidemiology, genetic recombination, and pathogenesis of coronaviruses. Trends Microbiol 2016;24:490-502.

2. Drosten C, Günther S, Preiser W, et al. Identification of a novel coronavirus in patients with severe acute respiratory syndrome. N Engl J Med 2003;348:1967-76.

3. Zaki AM, van Boheemen S, Bestebroer TM, et al. Isolation of a novel coronavirus from a man with pneumonia in Saudi Arabia. N Engl J Med 2012;367:1814-20.

4. Zhu N, Zhang D, Wang W, et al. A novel coronavirus from patients with pneumonia in China, 2019. N Engl J Med 2020;382:727-33.

5. World Health Organization. Summary of probable SARS cases with onset of illness from 1 November 2002 to 31 July 2003 2003. Available online: https://www.who.int/csr/ sars/country/table2004_04_21/en/

6. World Health Organization. Middle east respiratory syndrome coronavirus (MERS-CoV) 2019. Available online: https://www.who.int/emergencies/mers-cov/en/

7. Li Q, Guan $\mathrm{X}, \mathrm{Wu}$ P, et al. Early transmission dynamics in Wuhan, China, of novel coronavirus-infected pneumonia. N Engl J Med 2020;382:1199-207.

8. World Health Organization. Coronavirus disease 2019 (COVID-19) Situation Report-update 106 2020 [updated 5 May 2020]. Available online: https:// www.who.int/docs/default-source/coronaviruse/ situation-reports/20200505 covid-19-sitrep-106. pdf?sfursn=47090f63_2

9. Thomas-Rüddel D, Winning J, Dickmann P, et al. Coronavirus disease 2019 (COVID-19): update for anesthesiologists and intensivists March 2020. Anaesthesist 2020;69:225-35.

10. Wang D, Hu B, Hu C, et al. Clinical characteristics of 138 hospitalized patients with 2019 Novel CoronavirusInfected pneumonia in Wuhan, China. JAMA 2020;323:1061.

11. Martins-Filho PR, Tavares CSS, Santos VS. Factors associated with mortality in patients with COVID-19. A quantitative evidence synthesis of clinical and laboratory data. Eur J Intern Med 2020;76:97-9.

12. Henry BM, de Oliveira MHS, Benoit S, et al.
Hematologic, biochemical and immune biomarker abnormalities associated with severe illness and mortality in coronavirus disease 2019 (COVID-19): a meta-analysis. Clin Chem Lab Med 2020;58:1021-8.

13. Cao Y, Liu X, Xiong L, et al. Imaging and clinical features of patients with 2019 novel coronavirus SARS-CoV-2: A systematic review and meta-analysis. J Med Virol 2020;92:1449-59.

14. Vrsalovic M, Vrsalovic Presecki A. Cardiac troponins predict mortality in patients with COVID-19: A meta-analysis of adjusted risk estimates. J Infect 2020;81:e99-e100.

15. Lippi G, Lavie CJ, Sanchis-Gomar F. Cardiac troponin I in patients with coronavirus disease 2019 (COVID-19): Evidence from a meta-analysis. Prog Cardiovasc Dis 2020;63:390-1.

16. Lippi G, Wong J, Henry BM. Hypertension in patients with coronavirus disease 2019 (COVID-19): A pooled analysis. Pol Arch Intern Med 2020;130:304-9.

17. Kumar A, Arora A, Sharma P, et al. Is diabetes mellitus associated with mortality and severity of COVID-19? A meta-analysis. Diabetes Metab Syndr 2020;14:535-45.

18. Huang I, Lim MA, Pranata R. Diabetes mellitus is associated with increased mortality and severity of disease in COVID-19 pneumonia - A systematic review, metaanalysis, and meta-regression. Diabetes Metab Syndr 2020;14:395-403.

19. Pranata R, Huang I, Lim MA, et al. Impact of Cerebrovascular and Cardiovascular Diseases on Mortality and Severity of COVID-19 - Systematic Review, Metaanalysis, and Meta-regression. J Stroke Cerebrovasc Dis 2020;29:104949.

20. Pranata R, Lim MA, Huang I, et al. Hypertension is associated with increased mortality and severity of disease in COVID-19 pneumonia: A systematic review, meta-analysis and meta-regression. J Renin Angiotensin Aldosterone Syst 2020;21:1470320320926899.

21. Zuin M, Rigatelli G, Zuliani G, et al. Arterial hypertension and risk of death in patients with COVID-19 infection: systematic review and meta-analysis. J Infect 2020;81:e84-e86.

22. Sarma P, Kaur H, Kumar H, et al. Virological and Clinical Cure in Covid-19 Patients Treated with Hydroxychloroquine: A Systematic Review and MetaAnalysis. J Med Virol 2020;92:776-85.

23. Yang Z, Liu J, Zhou Y, et al. The effect of corticosteroid treatment on patients with coronavirus infection: a systematic review and meta-analysis. J Infect 
2020;81:e13-e20.

24. Tian W, Jiang W, Yao J, et al. Predictors of Mortality in Hospitalized COVID-19 Patients: A Systematic Review and Meta-Analysis. J Med Virol 2020;92:1875-83.

25. Parohan M, Yaghoubi S, Seraji A, et al. Risk factors for mortality in patients with Coronavirus Disease 2019 (COVID-19) infection: A systematic review and metaanalysis of observational studies. Aging Male 2020. doi: 10.1080/13685538.2020.1774748.

26. Moher D, Liberati A, Tetzlaff J, et al. Preferred reporting items for systematic reviews and meta-analyses: the PRISMA statement. PLoS Med 2009;6:e1000097.

27. Stang A. Critical evaluation of the Newcastle-Ottawa scale for the assessment of the quality of nonrandomized studies in meta-analyses. Eur J Epidemiol 2010;25:603-5.

28. Zhou F, Yu T, Du R, et al. Clinical course and risk factors for mortality of adult inpatients with COVID-19 in Wuhan, China: a retrospective cohort study. Lancet 2020;395:1054-62.

29. Wang L, He W, Yu X, et al. Coronavirus disease 2019 in elderly patients: Characteristics and prognostic factors based on 4-week follow-up. J Infect 2020;80:639-45.

30. Chen T, Wu D, Chen H, et al. Clinical characteristics of 113 deceased patients with coronavirus disease 2019: retrospective study. BMJ 2020;368:m1091.

31. Zhang F, Yang D, Li J, et al. Myocardial injury is associated with in-hospital mortality of confirmed or suspected COVID-19 in Wuhan, China: A single center retrospective cohort study. medRxiv 2020. doi: https://doi. org/10.1101/2020.03.21.20040121.

32. Yao Q, Wang P, Wang X, et al. Retrospective study of risk factors for severe SARS-Cov-2 infections in hospitalized adult patients. Pol Arch Intern Med 2020;130:390-9.

33. Wang D, Yin Y, Hu C, et al. Clinical course and outcome of 107 patients infected with the novel coronavirus, SARSCoV-2, discharged from two hospitals in Wuhan, China. Crit Care 2020;24:188.

34. Xu B, Fan CY, Wang AL, et al. Suppressed T cellmediated immunity in patients with COVID-19: A clinical retrospective study in Wuhan, China. J Infect 2020;81:e51-e60.

35. Zhang J, Liu P, Wang M, et al. The clinical data from 19 critically ill patients with coronavirus disease 2019: a single-centered, retrospective, observational study. Z Gesundh Wiss 2020. doi: 10.1007/s10389-020-01291-2.

36. Mehra MR, Desai SS, Kuy S, et al. Cardiovascular disease, drug therapy, and mortality in Covid-19. N Engl J Med 2020;382:e102.
37. Mehta V, Goel S, Kabarriti R, et al. Case fatality rate of cancer patients with COVID-19 in a New York Hospital System. Cancer Discov 2020;10:935-41.

38. Paranjpe I, Russak A, De Freitas JK, et al. Clinical characteristics of hospitalized Covid-19 patients in New York City. MedRxiv 2020. doi: 10.1101/2020.04.19.20062117.

39. Nowak B, Szymański P, Pańkowski I, et al. Clinical characteristics and short-term outcomes of patients with Coronavirus Disease 2019: A retrospective single-center experience of a designated hospital in Poland. Pol Arch Intern Med 2020;130:407-11.

40. Giacomelli A, Ridolfo AL, Milazzo L, et al. 30-day mortality in patients hospitalized with COVID-19 during the first wave of the Italian epidemic: A prospective cohort study. Pharmacol Res 2020;158:104931.

41. Yan X, Li F, Wang X, et al. Neutrophil to lymphocyte ratio as prognostic and predictive factor in patients with Coronavirus Disease 2019: A retrospective cross-sectional study. J Med Virol 2020;92:2573-81.

42. Fu L, Fei J, Xiang HX, et al. Analysis of death risk factors among 200 COVID-19 Patients in Wuhan, China: A hospital-based case-cohort study. SSRN 23 Mar 2020. Available online: http://dx.doi.org/10.2139/ssrn.3551430

43. Chen $M$, Fan $Y, W u X$, et al. Clinical characteristics and risk factors for fatal Outcome in Patients With 2019-Coronavirus Infected Disease (COVID-19) in Wuhan, China. 03 Mar 2020. Available online: http:// dx.doi.org/10.2139/ssrn.3546069

44. Yuan M, Yin W, Tao Z, et al. Association of radiologic findings with mortality of patients infected with 2019 novel coronavirus in Wuhan, China. PLoS One 2020;15:e0230548.

45. Borghesi A, Zigliani A, Golemi S, et al. Chest X-ray severity index as a predictor of in-hospital mortality in Coronavirus Disease 2019: A study of 302 patients from Italy. Int J Infect Dis 2020;96:291-3.

46. Lee LY, Cazier JB, Angelis V, et al. COVID-19 mortality in patients with cancer on chemotherapy or other anticancer treatments: A prospective cohort study. Lancet 2020;395:1919-26.

47. COVIDSurg Collaborative. Mortality and pulmonary complications in patients undergoing surgery with perioperative SARS-CoV-2 infection: An international cohort study. Lancet 2020;396:27-38.

48. Wölfel R, Corman VM, Guggemos W, et al. Virological assessment of hospitalized patients with COVID-2019. Nature 2020;581:465-9. 
49. Shi Y, Wang Y, Shao C, et al. COVID-19 infection: the perspectives on immune responses. Cell Death Differ 2020;27:1451-4.

50. Chan JW, Ng CK, Chan YH, et al. Short term outcome and risk factors for adverse clinical outcomes in adults with severe acute respiratory syndrome (SARS). Thorax 2003;58:686-9.

51. Wu C, Chen X, Cai Y, et al. Risk factors associated with acute respiratory distress syndrome and death in patients with Coronavirus Disease 2019 Pneumonia in Wuhan, China. JAMA Intern Med 2020;180:934-43.

52. Du RH, Liang LR, Yang CQ, et al. Predictors of mortality for patients with COVID-19 pneumonia caused by SARS-CoV-2: a prospective cohort study. Eur Respir J

Cite this article as: Xiang G, Xie L, Chen Z, Hao S, Fu C, Wu Q, Liu X, Li S. Clinical risk factors for mortality of hospitalized patients with COVID-19: systematic review and meta-analysis. Ann Palliat Med 2021;10(3):2723-2735. doi: 10.21037/apm-20-1278
2020;55:2000524.

53. Chen R, Liang W, Jiang $M$, et al. Risk factors of fatal outcome in hospitalized subjects with Coronavirus Disease 2019 from a nationwide analysis in China. Chest 2020;158:97-105.

54. WHO statement: Tobacco use and COVID-19. Retrieved May 12, 2020. Available online: https://www.who.int/ news-room/detail/11-05-2020-who-statement-tobaccouse-and-covid-19

55. Helms J, Tacquard C, Severac F, et al. High risk of thrombosis in patients with severe SARS-CoV-2 infection: a multicenter prospective cohort study. Intensive Care Med 2020;46:1089-98. 


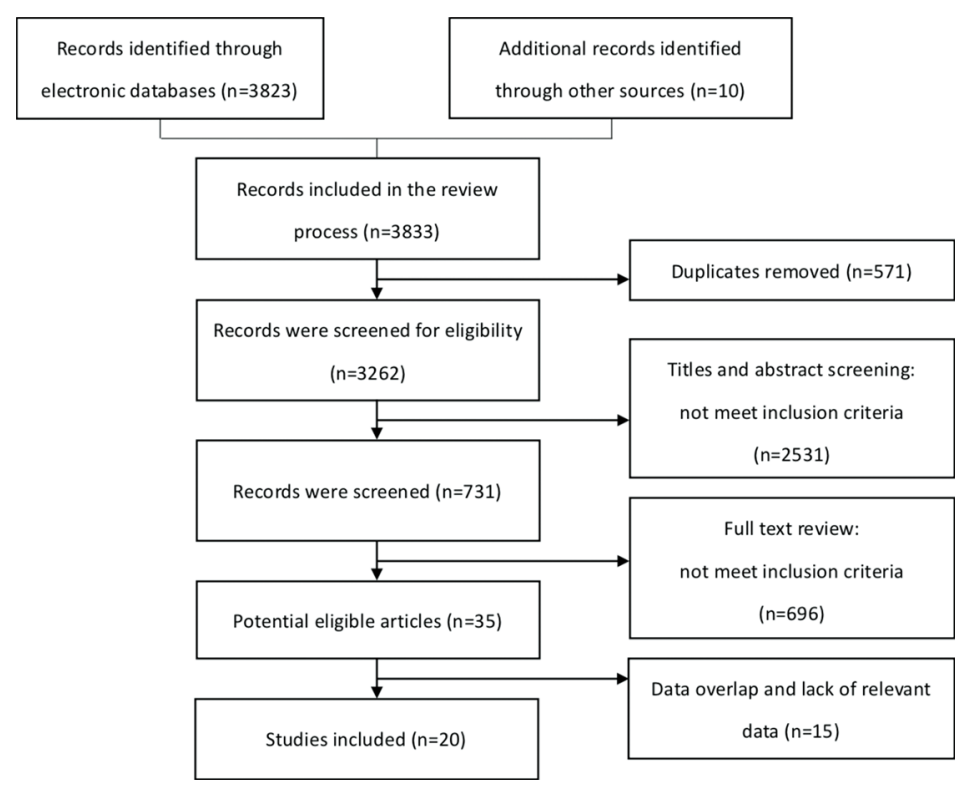

Figure S1 Flow diagram of the study selection process.

A

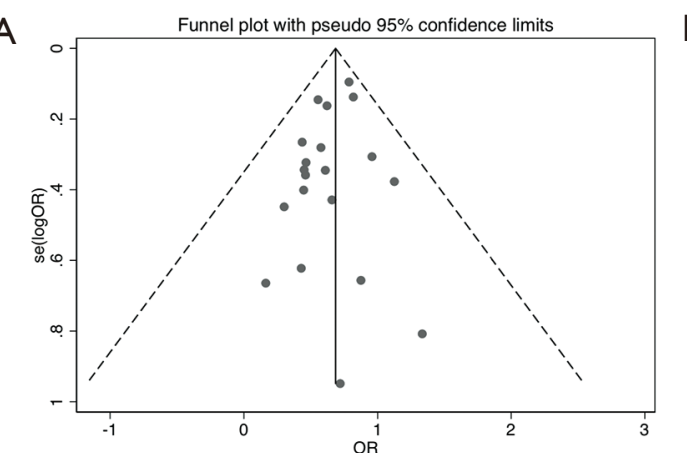

C

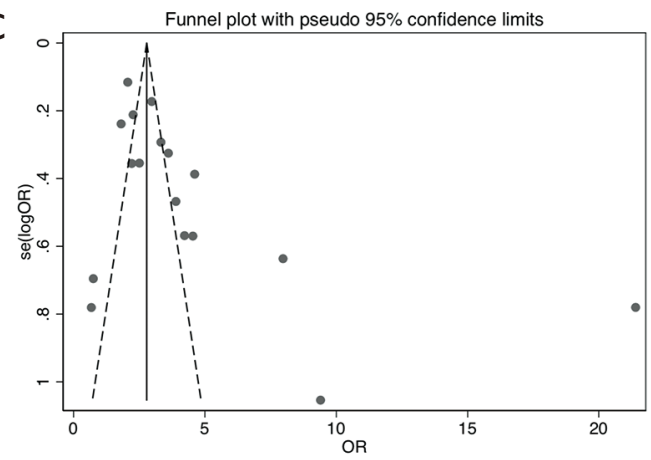

E

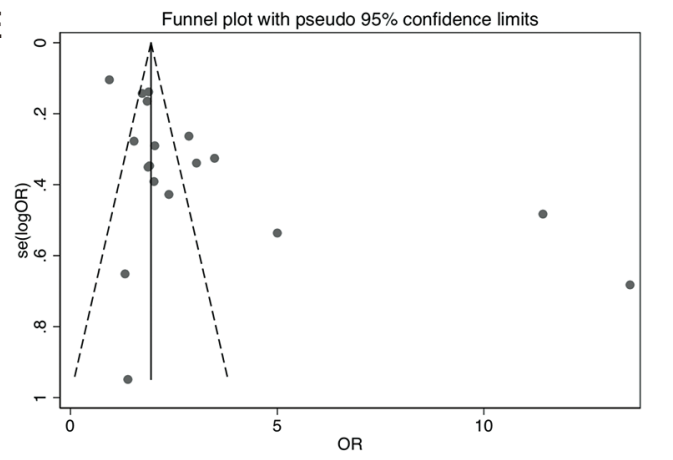

B

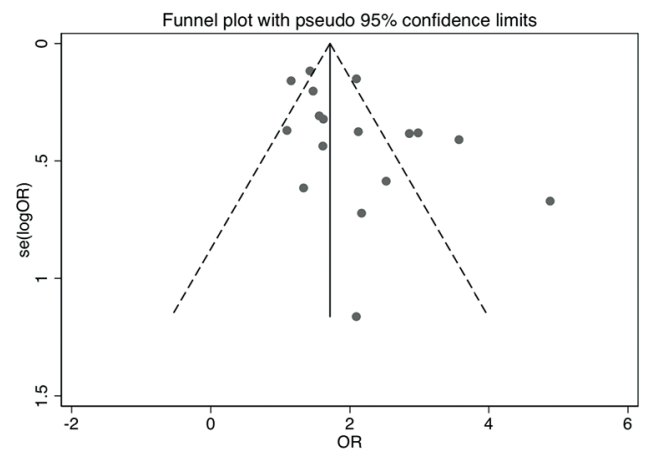

D

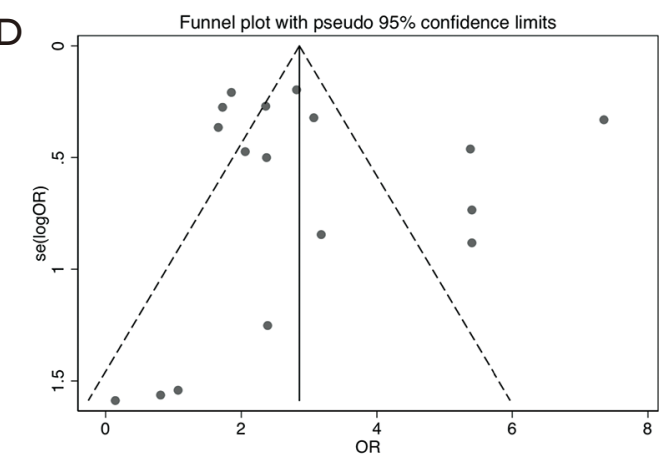

$\mathrm{F}$

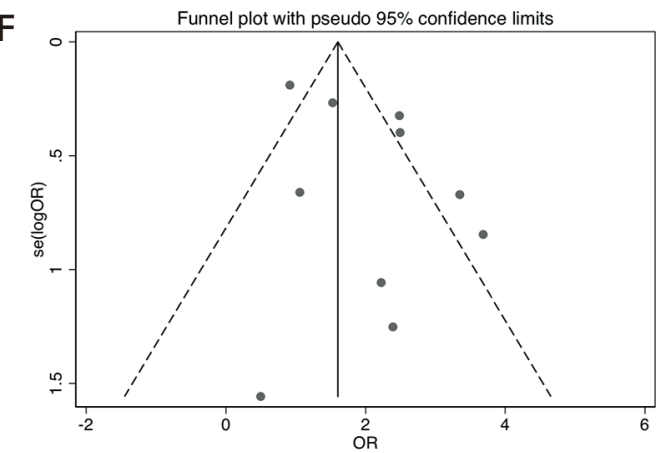

Figure S2 Egger's funnel plot of the comparisons of female (A), diabetes (B), cardiovascular disease (C), respiratory disease (D), hypertension (E) and cancer (F) between survivors and non-survivors. 

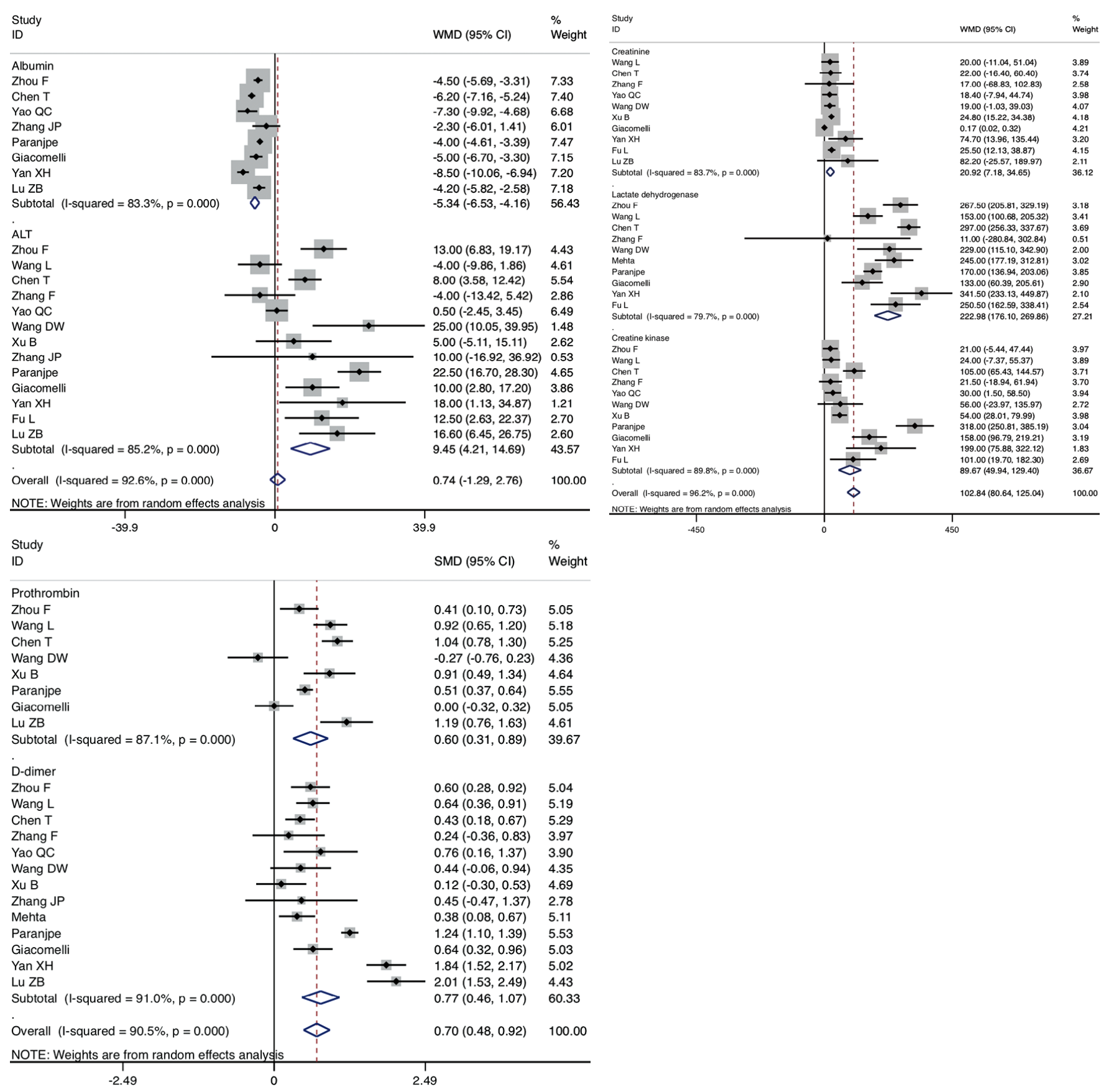

Figure S3 Forest plots of blood biochemistry in non-survivors vs survivors. 
Table S1 Quality control of the selected studies according to the criteria of the Agency for Healthcare Research and Quality (AHRQ).

\begin{tabular}{|c|c|c|c|c|c|c|c|c|c|c|c|c|}
\hline \multirow{2}{*}{ Study } & \multicolumn{12}{|c|}{ Quality assessment by AHRQ } \\
\hline & 1 & 2 & 3 & 4 & 5 & 6 & 7 & 8 & 9 & 10 & 11 & Score \\
\hline Zhou F (28) & $\star$ & $\star$ & $\star$ & $\star$ & $\star$ & $\star$ & $\star$ & $\star$ & $\star$ & $\star$ & ○ & 10 \\
\hline Wang L (29) & $\star$ & $\star$ & $\star$ & $\star$ & $\star$ & $\star$ & $\star$ & $\star$ & $\star$ & $\star$ & ○ & 10 \\
\hline Chen T (30) & $\star$ & $\star$ & $\star$ & $\star$ & $\star$ & $\star$ & $\star$ & $\star$ & $\star$ & $\star$ & O & 10 \\
\hline Zhang F (31) & $\star$ & $\star$ & $\star$ & $\star$ & $\star$ & $\star$ & $\star$ & O & $\star$ & ○ & ○ & 8 \\
\hline Yao QC (32) & $\star$ & $\star$ & $\star$ & $\star$ & $\star$ & $\star$ & $\star$ & $\star$ & $\star$ & O & O & 9 \\
\hline Wang DW (33) & $\star$ & $\star$ & $\star$ & $\star$ & $\star$ & $\star$ & $\star$ & $\star$ & $\star$ & O & O & 9 \\
\hline Xu B (34) & $\star$ & $\star$ & $\star$ & $\star$ & $\star$ & $\star$ & $\star$ & $\bigcirc$ & $\star$ & $\star$ & O & 9 \\
\hline Zhang JP (35) & $\star$ & $\star$ & $\star$ & $\star$ & $\star$ & $\star$ & O & O & $\star$ & $\star$ & O & 8 \\
\hline Mehra (36) & $\star$ & $\star$ & $\star$ & $\star$ & $\star$ & $\star$ & $\star$ & $\star$ & $\star$ & $\star$ & ○ & 10 \\
\hline Mehta (37) & $\star$ & $\star$ & $\star$ & $\star$ & $\star$ & $\star$ & $\star$ & $\star$ & $\star$ & $\star$ & ○ & 10 \\
\hline Paranjpe (38) & $\star$ & $\star$ & $\star$ & $\star$ & $\star$ & $\star$ & $\star$ & $\star$ & $\star$ & $\star$ & O & 10 \\
\hline Nowak (39) & $\star$ & $\star$ & $\star$ & $\star$ & O & $\star$ & $\star$ & $\star$ & $\star$ & $\star$ & $\bigcirc$ & 9 \\
\hline Giacomelli (40) & $\star$ & $\star$ & $\star$ & $\star$ & O & O & $\star$ & $\star$ & $\star$ & $\star$ & O & 8 \\
\hline Yan XH (41) & $\star$ & $\star$ & $\star$ & $\star$ & $\star$ & O & $\star$ & O & $\star$ & $\star$ & O & 8 \\
\hline Fu L (42) & $\star$ & $\star$ & $\star$ & $\star$ & $\star$ & $\star$ & $\star$ & O & O & $\star$ & O & 8 \\
\hline Lu ZB (43) & $\star$ & $\star$ & $\star$ & $\star$ & O & $\star$ & $\star$ & $\star$ & $\star$ & O & ○ & 8 \\
\hline Yuan ML (44) & $\star$ & $\star$ & $\star$ & $\star$ & $\star$ & $\star$ & $\star$ & $\star$ & ○ & O & $\bigcirc$ & 8 \\
\hline Borghesi (45) & $\star$ & $\star$ & $\star$ & $\star$ & $\star$ & O & $\star$ & $\star$ & ○ & $\star$ & O & 8 \\
\hline Lee Y W (46) & $\star$ & $\star$ & $\star$ & $\star$ & $\star$ & $\star$ & $\star$ & $\star$ & $\star$ & $\star$ & O & 10 \\
\hline Bhangu (47) & $\star$ & $\star$ & $\star$ & $\star$ & $\star$ & $\star$ & $\star$ & $\star$ & $\star$ & $\star$ & O & 10 \\
\hline
\end{tabular}

1, source of information; 2, inclusion and exclusion criteria; 3, time period; 4, consecutive subjects; 5 , mask of subjective components; 6 , quality assurance; 7 , explanation of exclusions; 8 , control of confounding factors; 9 , handling of missing data; 10 , completeness of data collection; 11 , follow-up. $\star$, present and score $=1 ; \bigcirc$, not present or unclear and score $=0$.

Table S2 Complications of patients with COVID-19

\begin{tabular}{|c|c|c|c|c|c|c|c|c|}
\hline Study & Sepsis & $\begin{array}{l}\text { Respiratory } \\
\text { failure }\end{array}$ & ARDS & Heart failure & Septic shock & $\begin{array}{c}\text { Acute cardiac } \\
\text { injury }\end{array}$ & $\begin{array}{l}\text { Acute kidney } \\
\text { injury }\end{array}$ & $\begin{array}{l}\text { Secondary } \\
\text { infection }\end{array}$ \\
\hline Zhou F (28) & $\begin{array}{c}54[100] \\
58[42]\end{array}$ & $\begin{array}{l}53[98] \\
50[36]\end{array}$ & 50 [93]; 9 [7] & 28 [52]; 16 [12] & 38 [70]; 0 [0] & 32 [59]; 1 [1] & 27 [50]; 1 [1] & 27 [50]; 1 [1] \\
\hline Wang L (29) & NA & NA & $\begin{array}{c}56[88] ; \\
15[6]\end{array}$ & 39 [65]; 33 [12] & $\begin{array}{l}3[5] ; \\
5[2]\end{array}$ & 39 [65]; 33 [12] & 17 [28]; 11 [4] & 49 [82]; 94 [34] \\
\hline Chen T (30) & $\begin{array}{c}113[100] \\
83 \text { [52] }\end{array}$ & $\begin{array}{c}\text { 18/35 [51]; } \\
0 / 32[0]\end{array}$ & $\begin{array}{c}113[100] ; \\
83 \text { [52] }\end{array}$ & $\begin{array}{c}41 / 83[49] \\
3 / 94[3]\end{array}$ & $\begin{array}{c}46[41] ; \\
0[0]\end{array}$ & $\begin{array}{l}\text { 72/94 [77]; } \\
\text { 18/109 [17] }\end{array}$ & 28 [25]; 1 [1] & NA \\
\hline Zhang F (31) & NA & NA & NA & NA & NA & NA & NA & NA \\
\hline Yao QC (32) & $\begin{array}{c}11 \text { [92]; } 24 \\
\text { [25] }\end{array}$ & NA & $\begin{array}{c}12 \text { [100]; } 33 \\
{[34]}\end{array}$ & NA & 6 [50]; 0 [0] & 6 [50]; 2 [2] & 7 [58]; 9 [9] & NA \\
\hline Wang DW (33) & NA & NA & $\begin{array}{c}17 \text { [89.5]; } 11 \\
\text { [12.5] }\end{array}$ & NA & 19 [100]; 3 [3.4] & 8 [42.1]; 4 [4.5] & 14 [73.7]; 0 [0] & 4 [21.1]; 1 [1.1] \\
\hline Xu B (34) & NA & NA & NA & NA & NA & NA & NA & $\begin{array}{c}12 \text { [42.9]; } \\
10[8.5]\end{array}$ \\
\hline Zhang JP (35) & NA & NA & NA & NA & NA & NA & NA & NA \\
\hline Mehra (36) & NA & NA & NA & NA & NA & NA & NA & NA \\
\hline Mehta (37) & NA & NA & NA & NA & NA & NA & NA & NA \\
\hline Paranjpe (38) & NA & NA & NA & NA & NA & NA & NA & NA \\
\hline Nowak (39) & NA & NA & $\begin{array}{c}30 \text { [65.2]; } 11 \\
{[8.9]}\end{array}$ & NA & 11 [23.9]; 6 [4.9] & NA & 10 [21.7]; 7 [5.7] & $\begin{array}{c}38 \text { [82.6]; } \\
49 \text { [39.8] }\end{array}$ \\
\hline Giacomelli (40) & NA & NA & NA & NA & NA & NA & NA & NA \\
\hline Yan XH (41) & NA & NA & NA & NA & NA & NA & NA & NA \\
\hline Fu L (42) & NA & NA & NA & NA & NA & NA & NA & NA \\
\hline Lu ZB (43) & NA & NA & $\begin{array}{c}31 \text { [100]; } 11 \\
\text { [12] }\end{array}$ & NA & 14 [45.2]; 0 [0] & $\begin{array}{c}25 \text { [80.6]; } 9 \\
{[9.8]}\end{array}$ & 15 [48.4]; 3 [3.3] & NA \\
\hline Yuan ML (44) & NA & NA & $\begin{array}{c}10[100] ; 1 \\
{[6]}\end{array}$ & NA & NA & NA & NA & NA \\
\hline Borghesi (45) & NA & NA & NA & NA & NA & NA & NA & NA \\
\hline Lee YW (46) & NA & NA & NA & NA & NA & NA & NA & NA \\
\hline Bhangu (47) & NA & NA & NA & NA & NA & NA & NA & NA \\
\hline
\end{tabular}

Data are $\mathrm{n}[\%]$ or $\mathrm{n} / \mathrm{N}[\%]$; showed as: non-survivors; survivors. ARDS, acute respiratory distress syndrome; NA, not available. 